\title{
How Co-op in Engineering Technology Proves to Strengthen Student Learn- ing and Fulfill Student Learning Outcomes
}

\section{Dr. Morteza Sadat-Hossieny, Northern Kentucky University}

MORTEZA SADAT-HOSSIENY is currently an associate professor and director of engineering technology programs at Northern Kentucky University. Dr. Sadat received his Bachelor of Science in Mechanical Power Engineering Technology from Oklahoma State University, Masters of Science in Manufacturing Engineering Technology from Murray State University and Ph.D. in Industrial Technology Education from Iowa State University. His areas of concentration are Computer Aided Design, Industrial Automation, and his research Interests are globalized engineering/technology education, engineering technology innovative curriculum development, outcome assessments, and refining program accreditation procedures.

\section{Dr. Mauricio Torres, Northern Kentucky University}

Dr. Torres received a B.S. in Business Administration from City University of Sao Caetano do Sul, B.S. in Mechanical Industrial Engineering from Braz Cubas University, Brazil, M.S. in Engineering Management and Ph.D. in Industrial and Systems Engineering from Florida International University. He has over 30 years of experience in heavy machinery manufacturing industry and currently he holds the position of Assistant Professor in the Mechanical Manufacturing Engineering Technology Program at Northern Kentucky University. His research interests are manufacturing processes, enterprise engineering and engineering education. 


\title{
How Completing a Co-Op in Engineering Technology Strengthens and Fulfills Student Learning Outcomes
}

\begin{abstract}
Students at Northern Kentucky University Engineering Technology programs are required to take at least one semester of a co-op class as one of the program requirements. As the course description states, this course provides students an opportunity to apply the knowledge and skills they are learning in the classroom to an employment position in business or industry. It allows students to test and refine career plans and interests; gain experience in their field of specialty before they begin searching for a permanent position; and build a network of professional contacts from which they may draw technical and employment information.

It is believed that, in order for an experience to be educational, it must possess continuity and interaction, with each experience leading to additional opportunities for further improvement and learning. Therefore, we believe that experiential opportunities such as co-op programs are a central component of the educational process, particularly in the field of Engineering Technology.

The methods involved in experiential learning emphasize that the source of the learning material is based on individual experiences and interactions in a real world setting, as opposed to the more traditional method utilized in the classroom and lectures. Co-op classes incorporate many elements of the case method of experiential learning as defined by Kolb [1], a method which has been widely used in a variety of disciplines.

Having overseen the course for a number of years, it has become apparent that experiential opportunities facilitate learning beyond the points mentioned above. Further evidence comes from student feedback, which demonstrates a sense of obtaining much deeper knowledge related to topics covered in their classes. Team work, punctuality, problem solving, and real world experience are just a few of the skills that are widely mentioned to be gained through co-op courses.
\end{abstract}

This paper will discuss the data obtained from following course outcomes for the EGT301 course (Co-op in Engineering Technology at NKU) as it pertains to the following points:

1. Applying knowledge and skills to industrial jobs.

2. Refining career plans and finding an area of interest within mechanical/manufacturing engineering.

3. Gaining real world industrial experience.

4. Building a network of professional contacts.

5. Learning how to identify, analyze and solve technical problems.

6. Learning to communicate effectively. 
This paper will evaluate course outcomes and investigate the resulting program outcomes that were attained. In addition, recommendations for how best to use co-op experiences to attain program outcomes will be discussed.

\section{Introduction}

Northern Kentucky University (NKU) currently offers two Bachelor of Engineering Technology (EGT) Programs, including Electronic Engineering Technology as well as Mechanical and Manufacturing Engineering Technology. In addition, the Kentucky Council on Postsecondary Education is in the process of approving a third degree that is expected to be completed by February 2016.

All of the programs at NKU require a minimum of 3 credit hours of co-op courses. Co-op course (EGT301) is part of the programs core requirements and mandatory for students to take at NKU. Taking the Co-op course one time, is the minimum requirement, students generally remain employed by the companies where they completed their co-op for longer than the required time period. It has also been noted that a greater number of students are working full-time in the field in which they are majoring and take the co-op courses primarily to satisfy the requirements of that major.

Before delving into the discussion of the topics mentioned in the abstract, there is a frequently asked question that should be discussed. Many students, parents, and NKU administrators have inquired about the differences between a co-op experience and an internship. Baumann [2], has clearly specified the difference between co-op and Internship as it is sated in the tables below. Baumann states, why should job seekers consider both? Co-Op and internship provides a unique perspective - he believes if students have the chance to do both, they should go for it

\section{Internships}

\begin{tabular}{|l|l|}
\hline & $\begin{array}{l}\text { Does EGT301 - have any of } \\
\text { the following characteristics? }\end{array}$ \\
\hline $\begin{array}{l}\text { Usually a one-time work (10-12 week) assignment, often } \\
\text { in the summer. }\end{array}$ & \\
\hline $\begin{array}{l}\text { Typically doesn't interfere with college classes due to } \\
\text { timing, but less training is given because of this. }\end{array}$ & \\
\hline $\begin{array}{l}\text { Can be full- or part-time, paid or unpaid, depending on the } \\
\text { employer and the career field. }\end{array}$ & \\
\hline $\begin{array}{l}\text { Undergraduate students (rising Junior/Senior) are eligible } \\
\text { in most cases. It's rare to find internships available at } \\
\text { larger companies for freshmen and graduating seniors. }\end{array}$ \\
\hline $\begin{array}{l}\text { You don't have to miss 1-2 semesters to complete an } \\
\text { internship. }\end{array}$ & \\
\hline
\end{tabular}


You'll have an edge over students who don't have experiential education gained through an internship. Internships are usually limited to one area of responsibility (marketing, human resources, IT, etc.).

Average GPA sought is 3.0, with 3.5 in some cases.

\section{Co-Ops}

\begin{tabular}{|l|c|}
\hline & $\begin{array}{l}\text { Does EGT301 - has any of } \\
\text { the following characteristics? }\end{array}$ \\
\hline $\begin{array}{l}\text { Co-ops are a joint venture between the university, a } \\
\text { selected employer, and the student. }\end{array}$ & $\checkmark$ In some cases \\
\hline $\begin{array}{l}\text { Traditionally at least three work terms alternated with } \\
\text { school terms, resulting in a 5-year degree program (it's } \\
\text { going to take longer to graduate, but additional valuable } \\
\text { experience is gained) }\end{array}$ & \\
\hline $\begin{array}{l}\text { Co-Ops are full-time, paid positions } \\
\text { In some cases }\end{array}$ \\
\hline $\begin{array}{l}\text { More training is offered through a Co-Op } \\
\text { Some Co-Ops are rotational, offering opportunities across } \\
\text { functions }\end{array}$ & Not necessarily true for \\
\hline Graduate students are eligible in most cases for Co-Ops & $\checkmark$ \\
\hline $\begin{array}{l}\text { Students frequently start at higher salaries and higher } \\
\text { levels of responsibility than interns. }\end{array}$ & $\checkmark$ \\
\hline
\end{tabular}

Employers hiring EGT301 students do not use these terms separately. Some of the companies may see an internship or co-op as interchangeable language.

\section{Applying Knowledge and Skills to Industrial Jobs.}

The core purpose of co-op is for students to apply knowledge that they have gained in the program to real world industrial jobs. Co-ops allow students to achieve a level of understanding of engineering topics in which they are capable of conducting the problem solving techniques required in the industrial setting. According to Jones, et. al. [3] placing students in actual jobs within industry where an advisory board members' is working on and provide access to, both physical and virtual (documents, models, etc.), allows a greater level of involvement for students and a more compelling, realistic experiences. 
The author's many years of teaching experience have demonstrated that students taking co-op or those that work full time and maintain good industry involvements are more motivated throughout their program of study.

\section{Refining Career Plans and Finding an Area of Interest Within Mechanical/Manufacturing Engineering}

Walmsley, et. al. [4] writes - universities use internships/co-ops to enable students to develop a range of skills and to help clarify and refine employment intentions and improve their career goals.

As individuals what we perceive at times is totally different than the reality of working full time in a profession. Often you hear individuals say "I would have liked to have been a researcher or an engineering designer, but I could not see myself working all my life in that setting." A co-op job allows students to try out the jobs they may wish to pursue in the future and to prepare for the possibility of working in those settings. After working in a manufacturing field, some students develop an interest in pursuing further knowledge in a specific field of manufacturing. Under the mechanical and manufacturing engineering technology programs, students can focus their studies by taking optional courses in design, quality, or tool design.

\section{Building a Network of Professional Contacts}

Evaluation of the experiences of engineering technology students at NKU has demonstrated that those students who obtain co-op positions early on in their academic careers have a much better success rate for acquiring jobs related to their own academic major. As [3] noted previously, industrial involvement in capstone courses or co-op courses has been shown to enrich students' experiences and lend to a greater number of job interviews and offers.

Co-op students at NKU are required to have an industrial supervisor during their co-op experiences. Industrial supervisors not only teach the student how to perform their jobs in industry, but in most cases they also take on the role of long-term mentorship for their student's future careers.

Although students are the primary beneficiaries of the co-op program and industry involvement, another role that these programs play is to facilitate relationships between faculty and industrial organizations and to strengthen the industrial advisory board recruitment for the department.

As one of the requirements for the co-op program, students are required to communicate with the faculty in charge of the course as well as their industrial supervisor to setup a job site visit. Speaking from the perspective of a faculty advisor, there are many benefits that are abundantly evident. When making industrial visits, I have gained much insight into what our students are doing and the opportunities that they have to learn about the industry, the type of product/services they manufacture/deliver. These visits and the feedback I receive from students allows me to improve my courses in order to better meet the needs of our constituencies. The 
interactions with industry also help us make better informed decision on curriculum changes and receive valuable advice through the feedback at the end of each semester.

\section{Learning how to identify, analyze and solve technical problems and how to communicate effectively.}

Jose A. Gavan, et. al. [5] in a study of internship performance outcomes, states that National Research Council (NRC) [6] in 2010 defined 3 categories of skills considered the underpinning of a broad range of jobs. The 3 skills were: cognitive skills, interpersonal skills, and intrapersonal skills.

- Cognitive skills: problem solving (non-routine), critical thinking, systems thinking, information/ ICT literacy, creativity, and learning to learn/meta-cognitive skills;

- Interpersonal skills: complex communication, social skills, teamwork/collaboration, social-cultural sensitivity, responsibility, tolerance for diversity, emotional/social intelligence, and leadership; and

- Intrapersonal skills: self-management, time management, self-development, selfregulation, adaptability, flexibility, executive functioning, core self-evaluation, work ethic, persistence, study skills, ethics \& integrity, and citizenship.

Gaven, et. al. further specifies: "Researchers agree that cognitive intelligence or technical skills are needed, but not sufficient to have success in executing complex professional tasks and that interpersonal and intrapersonal skills improve performance. Some authors hold that the cognitive skill is the basic determinant of labor market outcomes. In contrast, others researchers have stated that "Non-cognitive ability is as important, if not more important, than cognitive ability." Globalization and world class competitiveness requires teamwork skills, occupational competencies, applying theoretical learning in practical solutions, routine and non-routine problem solving, and the ability to deal with uncertainty, verbal and written communication skills, the understanding of needs of external and internal customers, and the ability to engage with external suppliers, among other skills."

The study concludes that interpersonal and intrapersonal skills are needed as well cognitive skills in executing complex technical jobs. Cognitive skills alone are not sufficient for success in todays' complex technical environments.

\section{The Application of Co-op Program Evaluation Findings Towards Continuous Improvement Practices.}

Similar to what Laingen, et. al [7] states, the continuous improvement process is integral to the accreditation and evaluation of the engineering technology curriculum at NKU. The mixed methods of experiential learning and co-op work examines these practices using co-op industry competency assessment feedback in the continuous improvement process. 
This paper examines how assessment rankings of the co-op experiences by students and employers has strengthened and supported competency achievement related to the ETAC-ABET [8] Criterion 3 (a,b,c,f,g,h,i,j) outcomes across the stated timeline of January to December 2015. Also demonstrated is the method by which acquired competencies are used to support continuous improvement of Engineering Technology programs curricula at NKU.

EGT 301 findings

\begin{tabular}{|c|c|c|c|}
\hline \multicolumn{4}{|c|}{ EGT 301 - Course Outcomes Assessment } \\
\hline Title of Course: & \multicolumn{2}{|l|}{ [Abstract] } & $859-572-5762$ \\
\hline Course Description: & \multicolumn{3}{|c|}{$\begin{array}{l}\text { This course provides students an opportunity to apply the knowledge and skills they are } \\
\text { learning in the classroom to an employment position in business or industry. It allows } \\
\text { students to test and refine career plans and interests; gain experience in their field of } \\
\text { specialty before they begin searching for a permanent position; and build a network of } \\
\text { professional contacts from which they may draw technical and employment information. } \\
\text { PREREQ: consent of instructor }\end{array}$} \\
\hline Location: & \multicolumn{3}{|c|}{ Highland Height Campus } \\
\hline Date of Class: & \multicolumn{3}{|l|}{$12 / 5 / 2014$} \\
\hline Class Times: & \multicolumn{3}{|c|}{ Course does not meet on campus } \\
\hline Equipment Needed: & \multicolumn{3}{|l|}{ Non on campus } \\
\hline Class Capacity: & \multicolumn{3}{|l|}{$15-20$} \\
\hline Component for Training: & \multicolumn{3}{|c|}{ Work in industry between 20 to 40 hours per week } \\
\hline Cost of Training: & \multicolumn{3}{|c|}{ Students are paid for their work in industry } \\
\hline \multicolumn{4}{|l|}{ Class Objectives / Outcomes } \\
\hline \multicolumn{4}{|c|}{$\begin{array}{l}\text { Course Outcomes } \\
\text { Students will: } \\
\text { 1. Apply knowledge and skills to industrial jobs } \\
\text { 2. Refine career plans and find the aspect of mechanical or } \\
\text { manufacturing job they like the best } \\
\text { 3. Gain real world industrial experience } \\
\text { 4. Build a network of professional contacts }\end{array}$} \\
\hline Information & \multicolumn{3}{|c|}{$\begin{array}{l}\text { Focus: --1-- } \\
\text { Course Outcomes Met } \\
\text { IV__ Analysis } \quad \text { V__Synthesis } \quad \text { VI_Evaluation }\end{array}$} \\
\hline
\end{tabular}




\section{This course will fulfill the following program student learning outcomes:}

Indicate if the outcome were met or not met

SO1. [a]An ability to select and apply the knowledge, techniques, skills, and modern tools of mechanical and manufacturing engineering technology to the design, manufacturing, testing, evaluation, and maintenance of mechanical and manufacturing systems;

SO2. [b] An ability to select and apply a knowledge of mathematics, science, engineering, and

MET technology to selection of materials, manufacturing processes, tooling, automation, production operations, maintenance, quality, industrial organization, management and statistics to solve mechanical and manufacturing problems;

SO3. [c] An ability to conduct standard tests and measurements of engineering materials, statics, dynamics, fluid power, and electronics;

SO6. [f] An ability to identify, analyze, and solve engineering technology problems

MET- need improvements

SO7. [g] An ability to apply written, oral, and graphical communication in both technical and nontechnical environments; and an ability to identify and use appropriate technical literature;

SO8. [h] An understanding of the need for and an ability to engage in self-directed continuing MET

MET- need improvements professional development;

SO9. [i] An understanding of and a commitment to address professional and ethical responsibilities including a respect for diversity;

SO10. [j] A knowledge of the impact of engineering technology solutions in a societal and global context; and

\begin{tabular}{|c|c|c|c|c|c|c|c|c|c|c|c|c|}
\hline \multicolumn{13}{|c|}{ Map of Course Competencies with Student Outcomes } \\
\hline \multirow{2}{*}{\multicolumn{2}{|c|}{ Course }} & $\begin{array}{c}\text { SO } \\
1\end{array}$ & $\begin{array}{c}\text { so } \\
2\end{array}$ & $\begin{array}{c}\text { So } \\
3\end{array}$ & $\begin{array}{c}\text { SO } \\
4\end{array}$ & $\begin{array}{c}\text { So } \\
5\end{array}$ & $\begin{array}{c}\text { SO } \\
6\end{array}$ & $\begin{array}{c}\text { So } \\
7\end{array}$ & $\begin{array}{c}\text { SO } \\
8\end{array}$ & $\begin{array}{c}\text { SO } \\
9\end{array}$ & S010 & SO11 \\
\hline & & a & b & c & d & e & f & g & h & i & j & k \\
\hline EGT 301 & Cooperative Education in Eng. Technology & 1 & 1 & 1 & & & 1 & 1 & 1 & 1 & 1 & \\
\hline
\end{tabular}

\section{Comparing students that were unable to successfully complete an off campus co-op course compared with students that completed at least one semester of a co-op course.}


All students in the engineering technology programs at NKU are required to take at least one coop course. Some students have not been successful in acquiring a co-op position in industry. In most cases these students are placed in non-paid jobs on campus. The followings feedbacks from both groups of students:

Student \# 1 -off-campus position

I started my coop with Cincinnati Incorporated on December 10th 2014. I have learned an enormous amount of information and skills while I have worked there. After I graduate I will start a full time job with Cincinnati Incorporated.

I. What were Objectives and Goals of the past 16 weeks?

a. Mental Processes used on the job.

I have used many processes on the job. I have had to think on the spot, plan out multiple projects and present those projects. I have also had to research many different topics in order to better understand and solve many different problems.

b. Work Output.

I worked forty hours just about every week since I started on December $10^{\text {th }} 2015$. I have drawn numerous wiring diagrams for multiple different machines. I have also drawn and manufactured a few different parts. I have assembled many different mechanical parts of machines and I have wired multiple different machines as well.

c. Interpersonal Relationships

While I have worked at Cincinnati Incorporated I have met a lot of good people. Have made a lot of friends as well. There isn't a person at Cincinnati Incorporated that I have not talked to, everybody from the janitors to Cristina Marsh who is the sole owner of the company. I have talked in front of many different people and have gotten along with everybody.

\section{d. Job Satisfaction}

I am very satisfied with my COOP. I was able to work on both electrical and mechanical stuff. Anything that I was interested I was able to stick my nose in making my COOP very satisfying.

II. How did you achieve the above objectives/goals?

a. How you have met objectives. Give examples of how you accomplished.

Everything that I had to draw I used Solid Edge. Solid Edge was difficult at first but I was able to figure it out after about a week. Solid Edge was a different CAD package than I have used in the past making it difficult at first. They started me out wiring electrical panels for their machines and if I had any questions there was always somebody there to guide me in the right direction. Starting out wiring these panels made it easier 
for when I started designing and drawing updated versions of the panels I built. I also did a lot of mechanical work as well. I drilled and tapped a few hundred holes for one of Cincinnati Incorporated's new laser enclosure. I also built one of Cincinnati Incorporated's Big Area Additive Machine's printing bed. This is one of the world's largest $3 \mathrm{~d}$ printers which required a lot of electrical and mechanical work. I recently designed an electrical system that lifts large sheets of metal up for our large press brakes.

b. Why did you not meet a certain objective?

I met all objectives. The only thing I wish I did different was that I should have started earlier.

III. How did this co-op experience help satisfy program criterions listed below.

a. Personal Maturity or Growth.

I have grown greatly with this co-op. I was able to gain competencies and skills while working at Cincinnati Incorporated. The co-op also made up for some of the things that I didn't learn at school.

b. Academic Application

I have had to apply almost everything that I have learned at NKU. I have also learned a lot of things that I didn't but should have learned at NKU.

c. Identification of Special Interest.

While working at Cincinnati Incorporated I have become very interested in machine control. Controlling and setting up servo drives to their corresponding motors is very interesting to me, it is something we did not learn in school but is very important in the industry. Also I have learned how noise effects machines and computer logic. This also has intrigued me greatly. This has led me to reach out and try to learn more about how to prevent electric noise and how to eliminate most of it.

d. Improvement in Technical Areas

This co-op has improved every skill that I had before. Cincinnati Incorporated has taught me an extreme amount of knowledge while working there, things that were never discussed in any classes.

e. Improvement of interpersonal Skill

I have improved many of my interpersonal skills. The main one that I feel that has improved is the ability to talk about more technical data in front of people. This skill has improved even more than I thought it ever could.

f. Significance of co-op assignment 
The significance of the co-op assignment is great. The co-op has been a great opportunity to learn new things and confirm the things I learned while in school. The coop also allowed me to try out the career field and confirmed that I would like electronic engineering. The co-op also gave me a foot in the door and led to a fulltime job after graduation.

IV. An Understanding of the need for and an ability to engage in self-directed continuing professional development.

During the co-op I have realized the need to pursue further education whether it be more school or through self-guided research. As I mentioned previously about electric noise. I have started to research more about electric noise and try to learn ways of defeating it. This also leads further interest in other fields.

V. An understanding of and a commitment to address professional and ethical responsibilities including a respect for diversity.

It is very important to be a professional and ethical. As engineers we are going to be in charge and responsible for a lot of things and very expensive equipment. With this responsibility it is important that we are doing the right thing even when nobody is looking.

VI. A knowledge of the impact of engineering technology solutions in a societal and global context.

Our solutions will impact everything around us. Our decisions or the way we design and build things that can either destroy a company, environment or even people. If we make good or right decisions we may make things a lot better.

VII. A commitment to quality, timeliness, and continuous improvement.

As I continue a career in engineering there will always be a need for continuous improvement. If one is not willing to improve themselves they will never succeed in the engineering field.

VIII. Formulation of next level objectives.

I will continue my education first by completing the MMET degree from NKU. I only need a few more classes in order to complete this degree. After I finish the MMET degree I will seek out a master's degree and then a doctorate degree. On top of this course of action I will continue self-guided research in order to improve myself and my skills making me a better engineer.

Student \# 2 - on-campus position

The company specializes in industrial and domestic air conditioning and heating as well as installation, repair, and sales of HVAC equipment. My responsibilities include responding to emergency calls requiring maintenance of HVAC systems, checking ovens, kitchen steamers, air handlers, and fans among other equipment. My other task involved working on the air handler AH5 and AH6. 
Feedback from this student at the end of spring 2014 semester - Besides the practical knowledge, this opportunity allowed me to garner the maturity expected of the work place. I learnt essential skills required for later jobs. By interacting with experienced professionals in this field, I left the department a more polished technician, something that I would not have gained through classroom attendance alone. The technical skills acquired proved to be more than the limitations of the classroom setting. I was able to understand the requirements and expectations of my professional field after school.

I have always wanted to work in an environment that offers challenging tasks in building systems. This opportunity at this department helped me in assessing and evaluating the suitability of my career preference and choice. With the help of the supervisor, I was able to learn about what employers are looking for from students and future employees. I was given vital skills and had the opportunity to meet new people such as coworkers, fellow students, technicians, and suppliers. This allowed me to hone my communication and interpersonal skills. All these experiences left me feeling confident on preparing for or entering future job markets and handling my first job responsibilities.

Student \# 3 -off-campus position

I am currently employed and have been working for Legrand since January 2014. In October of 2010 I started working for a company call NuVo Technologies located in Hebron KY, which was later bought by Legrand in 2013. NuVo is a whole-home audio company which started in the early 2000s

I had many goals and objectives in the last sixteen weeks. I address escalated customer cases which originated in Tech Support. If they are not able to resolve a customer's technical issue with one of our products, I take ownership of the case until the problem is resolved by the engineering team.

Another objective was to test software. I test software which operates on our products and test our products compatibility with third-party software. This testing allows me to solve customer issues, identify software bugs, and to help the engineering development teams.

Another goal and objective was to document solutions to technical issues in the tech support database. This helps tech support solve issues when the same issue arises for another customer.

I met my objective of addressing escalated tech support cases by first trying to reproduce the issue the customer was reporting. One large issue I had to help identify and resolve was an issue when streaming the Pandora music service on one of our products. Up to seven customers reported tracks constantly advancing before the music server would ever produce audio. Every streaming service (Pandora, SiriusXM, TuneIn, Spotify, etc.) has a software streaming protocol and they are all not the same. Streaming services can be affected if a customer's networking hardware or network settings have changed. I had to initiate remote support sessions, using Go To Assist, with customers to analyze network settings on their home wireless routers.

I met my objective of testing software by trying to reproduce software bugs. One example is two customers reported getting no audio output from one of our products when trying to listen to a line-in input device after listening to internet streaming radio. We started to see this happen occasionally during testing but could not reproduce the problem consistently. A procedure for $100 \%$ reproducibility for the bug had to be documented before the software developers could fix 
the issue. Having reproducible steps saves time and money for the software development team and allows more time for them to stay focused on developing rather than fixing software bugs.

The academic application on the job relates to software and electronic hardware. Having a basic understanding of programming languages and programs helps me to analyze logs from our system to have a better understanding when trying to discover software bugs and run regression tests. It also helps me to communicate with the software developers and have a better understanding on what they are doing on the development side. My knowledge in electronic hardware helps me understand design issues I have to investigate due to customer complaints. When I speak with a senior design engineer about hardware design to troubleshoot a problem, I have a good understanding on why an issue is occurring. My knowledge in these areas will continue to grow as I work more on software and hardware testing with the developers.

Spending the majority of my time on escalated cases gave me the opportunity to exercise my communication skills by interacting with customers and the engineering team members. Solving these customer problems requires me to communicate issues to engineers and communicate solutions to customers. To be able to do this effectively is critical in my position so resolutions can be found as quickly as possible for the customer.

The last sixteen weeks have been a good learning experience. I was able to learn more about our products through software testing and resolving customer issues. I discovered I prefer to work on the software testing side of the business more than the direct customer support in the form of a high level tech support position. My boss is going to work to get me more involved with software testing so that can be my primary focus. Working closer with the software development team will expand my knowledge in the area of software and software development. This will help me become a proficient software tester and will help my company deliver better products to the market.

\section{Conclusion}

The importance of co-op training programs in strengthening the relationship between employers and the higher education institutions is well documented and feedbacks received from employers' shows the importance of co-op in meeting the local job market demands [9]. It is also a known fact that the students who choose cooperative education option have higher CGPA and show a better achievement of learning outcomes [10].

Through the evaluation discussed in this paper we were able to assess the degree of academic success of students who fulfil the co-op requirement in different ways. To mention, few of the successes students reported were;

- looking forward to continue their education at the Masters level or above,

- learned how to work as part of diverse teams with diverse cultural background,

- learned new materials (self-directed continuing education).,

- conduct themselves at professional level,

- improved their communication skills,

- improved their interpersonal skills,

- be ethical no matter if someone is checking their work or not. 
The followings are some of the responses when industrial supervisors were asked; 1) In what area(s) do you find this employee's academic preparation unsatisfactory?

- knowledge and understanding of analytical tools such as basic stress calculation and report writing,

- he did not have much time in the field,

- business Management,

- none, but I have not observed his writing skills needs some improvement,

- none, Excel and CAD could be stronger, but he will improve on both over time. No worries there,

- although mechanical skills at the outset were somewhat lacking, with each task we performed they improve,

- I have not seen anything unsatisfactory in his academic preparedness, but there is room to grow.

- nothing comes to mind

2) Based on the job performance of their co-op employee, how NKU's engineering technology programs could be improved?

- I would like to see Siemens NX being taught as part of the program. Ryan is an advanced user however he was trained at his previous employer and not part of an academic program,

- no improvement necessary,

- by linking real manufacturing problems to student project programs coordinated with companies involved,

- as much co-op time as possible,

- I currently see no gaps in Richie's preparation for his co-op. Richie has been outstanding. I really could not have asked for much more in a co-op,

- maybe some more "hands on" to prepare the students,

- tailoring programs to specific industries may provide additional insight.

How experiential learning outcome attained would differ between programs with co-op, compared to programs that do not require co-op? Answer to this question is obvious and can be found looking at the key successes reported by students and the feedback received from their industrial supervisors.

Further education, learning to work as part of diverse teams, self-directed learning, building a network with other professionals in their field, develop better communication, and interpersonal skills and learn to be ethical under any circumstance are key findings in this paper.

The findings listed above, provide direct unfiltered measures to ETAC [11] criteria 3 (a, e, f, g, h, i, and k) and criteria 4 - continuous improvement student outcomes. 


\section{References}

[1] D. A. Kolb and e. al., "National Teaching Fellowship Schemes - Organizational Behavior; an experiential approach (5th edition)," Prentice Hall , 1991. [Online]. Available:

http://www.learningandteaching.info/learning/experience.htm. [Accessed 18 January 2016].

[2] K. Baumann, "Campus to Career - paying it forward, preparing the next generation of talent for careers of their dreems," 10 October 2010. [Online]. Available: http://campus-to-career.com/2010/10/05/co-op-vsinternship-what $\%$ E2\%80\%99s-the-difference/.

[3] J. W. Jones and M. Mezo, "Capstone = Team Teaching + Team Learning + Industry," in ASEE Annual Conference and Exposition, Indianapolic, IN, 2014.

[4] A. Walmsley, R. Thomas and S. Jameson, "Internships in SMEs and Career Intentions," Journal of Educaiton and Work, vol. 25, no. n2, pp. P 185-204, 2012.

[5] j. A. Galvan, E. casman, E. Fisher, I. Nair and M. J. Small, "Assessing the Role of 21st Century Skills on Internship Outcomes in a Steel," in ASEE Annual Conderence \& Exposition, Indianapolis, IN, 2014.

[6] M. Hilton, "Exploring the intersection of science education and 21st century skills: a workshop summary," National Academic Press, 2010.

[7] M. A. Laingen, S. A. Freeman and T. J. Brumm, "Examining the use of engineering internship workplace competency assessments," in American Society for Engineering Education, Seattle, WA, 2015.

[8] ETAC, 2013-2014 Criteria for Accrediting Engineering Technology Programs, ABET (Accreditation Board for Engineering and Technology), 2012.

[9] N. Brahimi, F. Dweiri, I. Al-Syouf and S. A. Khan, "Cooperative Education in an Industrial Engineering Program," in 6th International Forum on Engineeing Education, 2012.

[10] T. Elsarnagawy and A. Alhamwi, "Quality Assurance in Biomedical Engineering COOP-educational Training Program: Planning, Implementaion and Analysis.," Journal of King Saud University, 2011.

[11] ABET-ETAC, "Accreditation Crideria," [Online]. Available: http://www.abet.org/accreditation/accreditationcriteria/criteria-for-accrediting-engineering-technology-programs-2016-2017/. [Accessed 20 March 2016]. 